\title{
Кровосберегающая технология при хирургическом лечении митральных пороков сердца в условиях искусственного кровообращения
}

\author{
Гуменюк Б. Н., Попов В. В., Гуменюк О. Б., Списаренко С. П., Лазоришинец В. В.
}

ГУ «Национальный институт сердечно-сосудистой хирургии имени Н. М. Амосова НАМН» (Киев)

\begin{abstract}
Применение во время операций протезирования митрального клапана с ИК компонентов донорской крови связано с различными возможными осложнениями, требует поиска альтернативных мер во избежание их использования. В отделении хирургии приобретенных пороков сердца НИССХ НАМН с 01.01.2000 по 01.01.2017 выполнено изолированное протезирование митрального клапана у 717 пациентов, в лечении которых на госпитальном этапе не использовались компоненты донорской крови. Описана методика проведения анестезиологических и перфузиологических мероприятий при протезировании митрального клапана с ИК, а также особенности ведения в отделении интенсивной терапии. Госпитальная летальность составила $1,4 \%$, время пребывания в отделении интенсивной терапии - 54,2 4,7 часа, время пребывания в хирургическом стационаре - 7,9 $\pm 0,7$ суток. При выписке у этой группы больных наблюдалась умеренная анемия. Внедрение описанной методики позволило получить хороший клинический эффект, без трансфузионных осложнений на госпитальном этапе.
\end{abstract}

Ключевые слова: искусственное кровообращение, кровосберегающая технология, хирургическое лечение митрального порока.

Переливание компонентов донорской крови является, по сути, трансплантацией чужеродной ткани и сопряжено с риском развития различных посттрансфузионных реакций и осложнений иммунного и неиммунного характера [4, 8]. Существует опасность заражения инфекционными и вирусными заболеваниями (гепатит, СПИД, цитомегаловирус, сифилис, трансфузионный мононуклеоз, малярия и др.), количество которых постоянно растет [2, 3, 9]. Доказанным является факт иммуносупрессивного воздействия аллогемотрансфузий на организм реципиента [1, 5-7]. В последнее время клиницистам все чаще приходится сталкиваться с этическими и юридическими проблемами, связанными с отказом пациентов от аллогемотрансфузий в связи с сомнениями в безопасности компонентов донорской крови и по религиозным убеждениям [10].

Следует также указать на низкую функциональную эффективность донорской эритроцитарной массы в связи с секвестрацией 25-30\% переливаемых эритроцитов и сниженным содержанием в них 2,3-дифосфоглицерата (2,3-ДФГ). В этой связи гемоглобин хоть и присоединяет кислород, но крайне слабо отдает его тканям. Поэтому перелитая донорская кровь незначительно улучшает транспорт кислорода к тканям [1-7]. В этой связи поднятый в работе вопрос о возможностях кровосберегающих технологий является крайне актуальным.

Цель работы - изучить современные возможности бескровной методики хирургического лечении митральных пороков (МП) в условиях искусственного кровообращения (ИК).
Материалы и методы. В анализируемой работе представлены результаты наблюдения 717 пациентов, находившихся на лечении в отделении хирургии приобретенных пороков сердца НИССХ имени Н. М. Амосова за период с 01.01.2004 до 01.01.2017 и оперированных в условиях искусственного кровообращения по поводу митральных пороков.

Bсе прослеженные пациенты были разделены на две группы: основная группа - 627 больных с митральным пороком сердца, у которых операция была выполнена без применения препаратов донорской крови и ее компонентов. В группе применялись различные варианты кровосберегающих методик, а также не использовались препараты донорской крови и ее компоненты на всех этапах послеоперационного периода. Группа сравнения - 90 больных с той же патологией, у которых методики кровосбережения не применялись, а использовалась донорская кровь и ее компоненты как в интра-, так и в послеоперационном периоде.

В основную группу включено 627 пациентов, в том числе $237(37,4 \%)$ мужчин и $390(62,6 \%)$ женщин в воз-

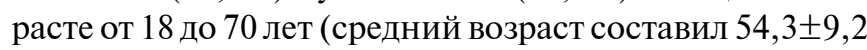
года). В группу сравнения вошли 90 пациентов, в том числе $40(44,4 \%)$ мужчин и $50(55,6 \%)$ женщин в воз-

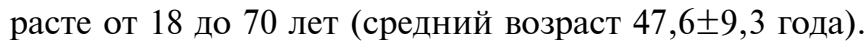
Всем была выполнена коррекция МП в условиях ИК.

У 398 (63,5\%) пациентов основной группы, как и у 71 (78,9\%) пациентов группы сравнения, превалирует изолированное протезирование митрального клапана (ПМК) без сопутствующих процедур. 


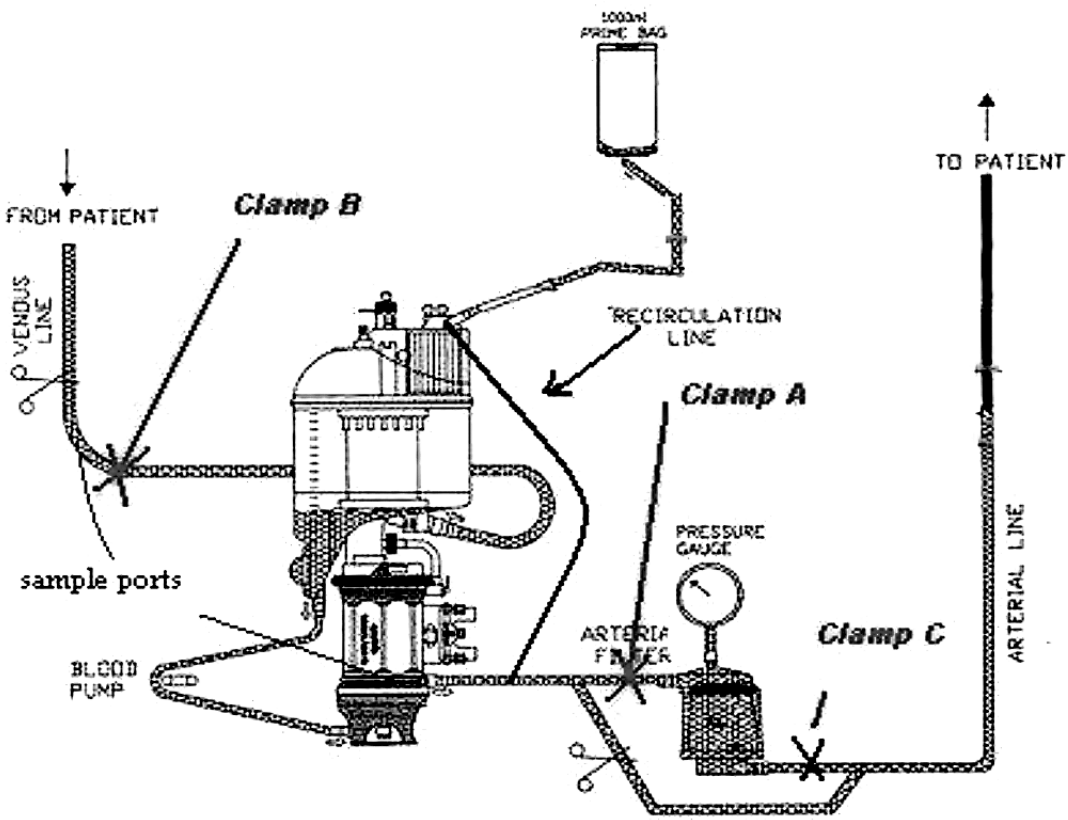

Рис. 1. Депонирование аутокрови в АИК из аортальной магистрали до (RAP) начала перфузии. Вариант кровосбережения «Б»

Таким образом, у 297 (47,5\%) пациентов удалось депонировать кровь на цитрате в дозе 400 мл и более до начала ИК с восполнением объема $10 \%$ раствором рефортана по отношению к крови 1:1 (вариант кровосбережения «А»). Резервирование аутокрови на предперфузионном этапе составило $465,2 \pm 119,9$ мл, т. е. $11,4 \pm 3,2 \%$ объема циркулирующей крови (ОЦК). После эксфузии аутокрови гемоглобин снижался с $139,2 \pm 15,2$ г/л до $129,4 \pm 15,3$ г/л, гематокрит - с $0,43 \pm 0,03$ до $0,38 \pm 0,04$, а белок - с $73,2 \pm 6,7$ г/л до $59,2 \pm 7,2$ г/л, что являлось безопасным и существенно не снижало кислородную емкость крови.

Нами были проведены сравнительные исследования состояния аутокрови при ее эксфузии в консерванте «Глюгицир» (основная группа) и состояния донорской эритроцитарной массы, использованной в группе сравнения перед инфузией пациентам (табл. 1).

Как видно из табл. 1, показатели $\mathrm{pH}$ и $\mathrm{BE}$ аутокрови и донорской эритроци-

В основной группе были разработаны и внедрены методики, направленные на кровосберегающие технологии. Дабы исключить осложнения на всех этапах операции, проводился тщательный мониторинг как гемодинамики, так и оценки состояния газов и т. п.

Лишь после трехлетних наработок (2000-2003 гг.) нам удалось получить целостную картину и создать методологическую базу для безопасного проведения операций. Так, важным элементом в основной группе явилось стимулирование диуреза, стартовавшее с начала операции в дозе 1 мг/кг фуросемида и $0,15-0,3$ г/ кг маннита. Введение проводилось внутривенно в течение получаса на вводном наркозе. Если величина гематокрита была более 0,4 , то это создавало возможность для депонирования крови на цитрате до начала ИК (вариант кровосбережения «А»).

Чем выше исходный уровень гематокрита, тем большая величина аутокрови могла быть депонирована. Ценность собранной таким образом аутокрови в том, что она полностью сохраняет все свои свойства на протяжении примерно двух часов (время искусственного кровообращения), не содержит гепарина и быстро позволяет восстановить гемостаз при введении протамин сульфата. Резервирование аутокрови по варианту «А» представляет собой поэтапный забор аутокрови в емкость с цитратным консервантом от момента разреза кожи до введения гепарина. Забор производился через артерию (a.radialis) (предпочтительнее в последнее время) либо через центральный венозный катетер в течение примерно 30 минут под строгим контролем АД (рис. 1). тарной массы достоверно не отличаются. Однако наблюдается достаточно значимое различие показателей оксигенации в аутокрови, собранной на глигицире из a.radialis и соответственно невысокие показатели оксигенации в донорской эритроцитарной массе $(\mathrm{p}<0,001)$.

Срок хранения донорской эритроцитарной массы был невелик и составлял $3,7 \pm 0,7$ дня. Несмотря на идентичные изменения кислотно-основного состояния аутокрови, собранной на глюгицире, и донорской эритроцитарной массы, переливание аутокрови существенно лучше для пациента, поскольку в аутокрови лучшие

\section{Таблица 1}

Кислотно-основное состояние аутокрови и донорской эритроцитарной массы

\begin{tabular}{|c|c|c|c|}
\hline & $\begin{array}{c}\text { Аутокровь на } \\
\text { «Глюгицире» } \\
(n=25)\end{array}$ & $\begin{array}{c}\text { Донорская } \\
\text { эритроцитарная } \\
\text { масса }(n=21)\end{array}$ & \\
\hline Показатель & $\begin{array}{c}\text { Перед реинфу- } \\
\text { зией }\end{array}$ & Перед реинфузией & $p$ \\
\hline $\mathrm{pH}$ & $6,89 \pm 0,2$ & $6,89 \pm 0,08$ & 0,052 \\
\hline $\begin{array}{l}\mathrm{pCO}_{2}, \mathrm{MM} \\
\text { рт. ст. }\end{array}$ & $73,4 \pm 9,2$ & $58,0 \pm 19,7$ & 0,001 \\
\hline $\begin{array}{l}\mathrm{pO}_{2}, \mathrm{MM} \\
\text { рт. ст. }\end{array}$ & $153,3 \pm 22,1$ & $39,86 \pm 7,0$ & $<0,001$ \\
\hline $\mathrm{BE}$ & $-19,5 \pm 3,9$ & $-22,5 \pm 2,5$ & 0,774 \\
\hline $\mathrm{SO}_{2}, \%$ & $95,7 \pm 1,8$ & $45,0 \pm 4,6$ & $<0,001$ \\
\hline $\begin{array}{l}\text { Время } \\
\text { хранения, } \\
\text { мин. }\end{array}$ & $205,4 \pm 31,8$ & $5005,7 \pm 2755,6$ & $<0,001$ \\
\hline
\end{tabular}




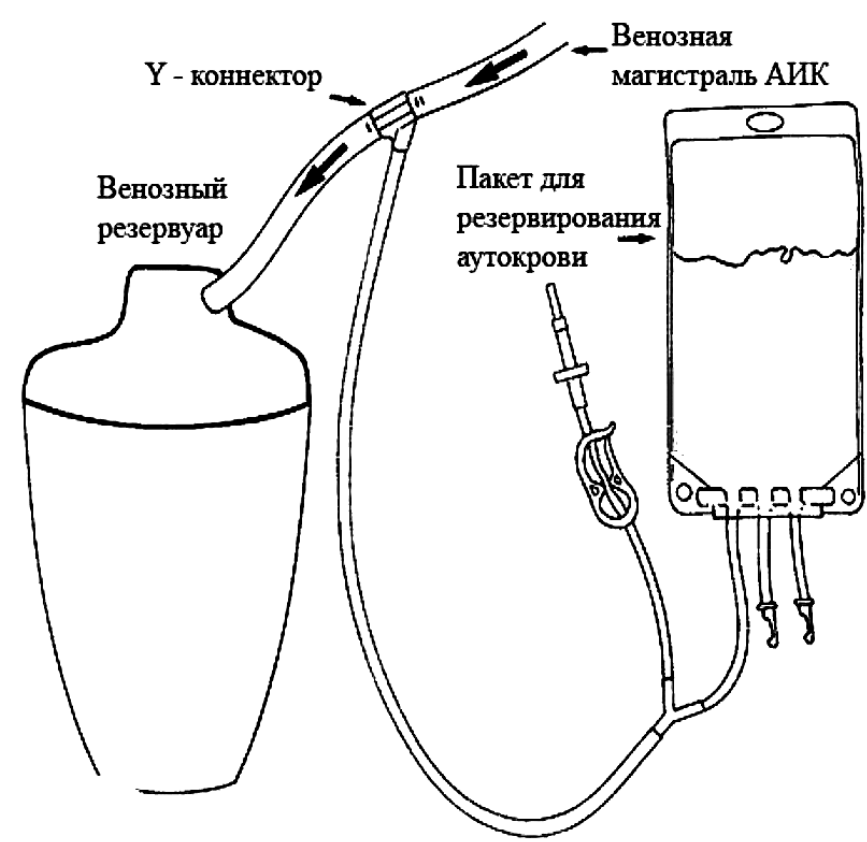

Рис. 2. Депонирование перфузата в АИК из венозной магистрали во время перфузии. Вариант кровосбережения «В»

показатели оксигенации, минимальный срок хранения которой составляет 230,6士54,8 мин., и, кроме того, собственная кровь пациента, содержащая полный набор факторов свертывания и активные тромбоциты [3, 7, 8].

После канюлирования аорты выполняли процедуру под названием retrograde autological priming (RAP) у 96 пациентов (вариант кровосбережения «Б»). C помощью варианта кровосбережения Б (RAR) удалось вытеснить из резервуара АИК 514,1土136,3 мл, что составило $10,8 \pm 4 \%$ от ОЦК.

Это было возможно при устойчивой гемодинамике, при весе пациента 80 кг и более и при величине гематокрита (в последнем анализе) не менее 0,36. При этом производился забор гепаринизированной крови из артериальной магистрали АИК, при котором кровь пациента собиралась в резервуар оксигенатора, вытесняя исходный бескровный перфузат, собираемый перфузиологом в отдельный резервуар (рис. 1).

Таблица 2

Количество сбора крови в группах резервирования

Группы

резервирования Эксфузия крови (Мл) RAP (Мл)

\begin{tabular}{|c|c|c|c|c|c|}
\hline «A» & $495,2 \pm 129,9$ & & & $495,2 \pm 129,9$ & $10,4 \pm 2,8$ \\
\hline «A+Б» & $414,7 \pm 93,1$ & $555,8 \pm 129,8$ & & $970,5 \pm 222,9$ & $22,5 \pm 4,7$ \\
\hline «A+B» & $447,2 \pm 91,2$ & & $501,9 \pm 159,9$ & $949,1 \pm 251,1$ & $19,1 \pm 5,1$ \\
\hline$« A+B+B »$ & $490,5 \pm 144,6$ & $573,8 \pm 185,5$ & $492,9 \pm 143,4$ & $1557,2 \pm 473,5$ & $29,2 \pm 8,9$ \\
\hline «B» & & & $495,8 \pm 144,8$ & $495,8 \pm 144,8$ & $11,1 \pm 3,3$ \\
\hline
\end{tabular}




\section{Таблица 3}

Варианты резервирования аутокрови

\begin{tabular}{lcc} 
& \multicolumn{2}{c}{ Количество пациентов } \\
\cline { 2 - 3 } Группа резервирования & $\mathbf{n}$ & \% \\
\hline Вариант «А» & 293 & 46,7 \\
\hline Вариант «А+Б» & 46 & 7,3 \\
\hline Вариант «А+B» & 143 & 22,8 \\
\hline Вариант «А+Б+B» & 56 & 9,0 \\
\hline Вариант «В» & 70 & 11,2 \\
\hline Вариант «Б» & 11 & 1,8 \\
\hline Вариант «Б+В» & 8 & 1,2 \\
\hline Итого: & 627 & 100,0
\end{tabular}

сталлоидного раствора Святого Томаса с добавлением $22,0 \%$ аутокрови, а также раствора Кустодиола. Введение кардиоплегии, как правило, выполнялось ретроградным путем подачи кардиоплегии в сочетании с наружным охлаждением сердца.

Во время ИК контролировались параметры анти-

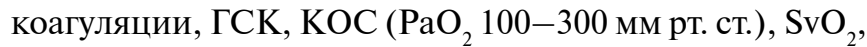
содержание электролитов плазмы, глюкозы и лактата крови, гемоглобина, гематокрита, белка, глубина анестезии, диурез (200 мл/ч) при гемодилюции, температура, ЦВД (отрицательное), АДср (50-90 мм рт. ст.).

После завершения коррекции порока и остановки аппарата ИК оставшееся содержимое резервуара АИК возвращалось в пациента, восполняя ОЦК под строгим контролем гемодинамики, чтобы не перегрузить сердце. Как правило, на этом этапе активно применяется изокет (0,5 мкрг/кг/мин.) с целью максимально восполнить по аортальной магистрали перфузат из оксигенатора в пациента. Если же данная процедура ограничена в своих возможностях, то оставшийся перфузат из оксигенатора собирался во флаконы, после чего сразу же переливался внутривенно пациенту. Безвозвратная кровопотеря на этом сегменте операции (остаток в резервуаре АИК) была минимизирована до 20-25 мл. Тщательный хирургический гемостаз выполнялся на всех этапах операции.

Восновной группе время ИК составило $96,2 \pm 20,4$ мин, время пережатия аорты $-62,3 \pm 15,5$ мин., а в группе сравнения $-96,5 \pm 14,2$ мин. и $62,3 \pm 15,2$ мин. (p>0,05).

Одним из принципов бескровного проведения операции с ИК является отсутствие выраженной гемоди- люции на всех этапах проведения коррекции. Это позволяло поддерживать водный баланс по жидкости до начала перфузии в пределах $0+300,0$, переливая лишь $6 \%$ рефортан в дозе около 400 мл (как восполнение на забор крови) и выходя почти на нулевой водный баланс к концу операции. Очень важно минимизировать водную преднагрузку на предперфузионном этапе. В подавляюшем большинстве случаев для этой цели $6 \%$ раствора 400 мл рефортана вполне хватало.

На этапе искусственного кровообращения и к концу перфузии водный баланс по жидкости был не выше $+1500,0$ мл, а к концу операции за счет активного диуреза баланс по жидкости, как правило, приводился к нулю. Вводился протамин сульфат в расчетной дозе. С целью улучшения гемостаза гордокс вводился в конце операции в дозе 20 000-30 000 ЕД/кг веса, а эпсилон-аминокапроновая кислота - 200 мг/кг, этамзилат в дозе 30 мг/кг.

Результаты и их обсуждение. В анализируемых группах умерших на госпитальном этапе не было. Отсутствие аллогемотрансфузий у пациентов основной группы способствовало снижению количества послеоперационных инфекционных осложнений по отношению к группе сравнения с 9,9\% (n=9/90) до $1,2 \%(n=7 / 627)$, длительности пребывания на искусственной вентиляции легких - с 12,3 $\pm 8,4$ часа до $6,7 \pm 2,3$ часа, а длительности пребывания в отделении интенсивной терапии c $116,3 \pm 45,2$ часа до $58,4 \pm 12,4$ часа $(\mathrm{p}<0,05)$. Таким образом, предложенные методики кровосбережения позволили улучшить результаты операций хирургической коррекции митральных пороков в основной группе.

Снижение интраоперационной кровопотери является одной из основных задач бескровного обеспечения операций. В ходе проведения сравнительного анализа объема интраоперационной кровопотери мы выяснили, что в основной группе эти показатели были значительно меньше, чем в группе сравнения: $261,2 \pm 33,8$ мл и $533,1 \pm 131,6$ мл $(\mathrm{p}<0,05)$. Данные по объему кровопотери представлены в табл. 4.

В группе сравнения донорская кровь и плазма применялась на всех этапах операции у 90 (100\%) пациентов и в отделении интенсивной терапии - у 48 $(53,3 \%)$ больных. При этом в группе сравнения в операционной было перелито суммарно 24052 мл эритроцитарной массы, что в пересчете составляет 267,2 мл на одного человека, и 30585 мл свежезамороженной

\section{Таблица 4}

Интраоперационная кровопотеря у кардио-хирургических больныхи экссудация по дренажам в ОИТ

\begin{tabular}{lcccc} 
& Основная группа (n=227) & \% от ОЦК & Группа сравнения (n=90) & \% от ОЦК \\
\hline Интраоперационная кровопотеря, мл & $185,5 \pm 34,4$ & $4,1 \pm 0,6$ & $421,1 \pm 83,5^{*}$ & $8,9 \pm 1,8$ \\
\hline Экссудация по дренажам, мл & $75,7 \pm 39,4$ & $1,3 \pm 0,5$ & $112,0 \pm 48,1$ & $2,3 \pm 1,0$ \\
\hline Итого, мл & $\mathbf{2 7 1 , 2 \pm 3 3 , 8}$ & $\mathbf{5 , 4 \pm 1 , 5}$ & $\mathbf{5 3 3 , 1 \pm 1 3 1 , 6}$ & \\
*p $<0,05$ & & &
\end{tabular}


плазмы, что также соответствует 340 мл на человека. В этой группе было использовано 32317 мл эритроцитарной массы, что в пересчете составило 359 мл на одного пациента, и 44510 мл свежезамороженной плазмы, что составляет в пересчете 495 мл на одного пациента.

Важным критерием кислородной емкости крови являлся показатель уровня гемоглобина на этапах коррекции. Динамика изменения показателей гемоглобина на всех этапах как в основной группе, так и в группе сравнения представлена в табл. 5 .

Как следует из данных табл. 4, во всех группах на всех этапах коррекции величина гемоглобина была адекватной и соответствовала безопасному уровню кислородной емкости крови, о чем свидетельствует отсутствие полиорганной недостаточности и клинически значимых осложнений на госпитальном этапе.

Выводы. Рутинно внедренная в клиническую практику вышеописанная методика бескровной хирургии при коррекции МП в условиях ИК позволила нам получить хороший клинический эффект, без трансфузионных осложнений на госпитальном этапе [8-10]. Вероятность ее использования снижается у пациентов с весом 60 кг и менее, наличием анемии (гемоглобин 110 г/л и менее) и в старшей возрастной группе (65 лет и старше). С достаточной осторожностью следует применять бескровную методику у пациентов с полиорганной недостаточностью, исходным значимым поражением головного мозга после ранее перенесенного нарушения мозгового кровообращения.

Критериями показаний к интраоперационному резервированию аутокрови при операциях хирургической коррекции митральных пороков в условиях ИК являются:

а) анамнестические: отсутствие в анамнезе указаний на анемию и отмена лекарственных средств, влияющих на свертывание крови за 7 дней до операции; б) исходные лабораторные показатели: гемоглобин $\geq 120$ г/л, гематокрит $\geq 40$, тромбоциты $\geq 170 Ч 10^{9} /$ л, эритроциты $\geq 4,0 Ч 10^{12} /$ л, белок $\geq 60$ г/л; в) показатели гемодинамики после вводного наркоза: ЦВД $\geq 4$ мм рт. ст. и АДср $\geq 90$ мм рт. ст. при исходном ОЦК $\geq 4,4 \pm 0,7$ л.

Применяемые варианты интраоперационного резервирования аутокрови при операциях хирургической коррекции митральных пороков в условиях ИК в комплексе с другими методами показали свою эффективность, что позволило отказаться от применения донорской крови и ее компонентов. Наиболее оптимальные показатели наблюдались при варианте резервирования «А+Б+В» и констатировали статистически значимое увеличение количества тромбоцитов на момент выписки на 20,4 \% по сравнению с исходными данными $(\mathrm{p}<0,05)$.

Эксфузия крови в объеме 10-29\% от ОЦК при операциях хирургической коррекции митральных пороков сердца в условиях ИК не приводит к снижению доставки и потребления кислорода и развитию метаболического и лактатацидоза. Гемодинамические параметры при этом оставались стабильными.

КОС аутокрови, собранной на глюгицире, лучше, чем КОС ЭМ. В эксфузируемой аутокрови в результате выхода из сосудистого русла и попадания в нефизиологичные условия хранения в среде на основе цитрата натрия, как и в ЭМ, происходят первичные нарушения, резко отличающиеся от физиологической нормы. Перфузат, резервируемый после гепаринизации в емкость без цитратного антикоагулянта, хранится в более физиологичных условиях. Отсутствие аллогемотрансфузий у пациентов основной группы способствовало снижению количества послеоперационных инфекционных осложнений с 7,7\% до $1,2 \%$ по отношению к группе сравнения.

Длительность ИВЛ и длительность пребывания в ОИТ в основной группе по отношению к группе сравнения снизились $(\mathrm{p}<0,05)$. Все эти показатели и значимое уменьшение интраоперационной и послеоперационной кровопотери в основной группе по отношению

Таблица 5

Динамика изменений показателей $\mathrm{Hb}$ (2/л) в группах резервирования и группе сравнения на всех этапах

\begin{tabular}{|c|c|c|c|c|c|c|c|}
\hline \multirow[b]{2}{*}{ Группы } & \multicolumn{7}{|c|}{ Этапы } \\
\hline & $\begin{array}{l}\text { Начало } \\
\text { наркоза }\end{array}$ & $\begin{array}{c}\text { Начало } \\
\text { операции }\end{array}$ & Начало ИК & $\begin{array}{c}\text { Окончание } \\
\text { ИК }\end{array}$ & $\begin{array}{c}\text { Конец } \\
\text { операции }\end{array}$ & $\begin{array}{c}\text { 2-е сутки } \\
\text { после операции }\end{array}$ & Выписка \\
\hline Вариант «A» $(n=293)$ & $135,5 \pm 16.0$ & $130,5 \pm 16,8$ & $96,2 \pm 16,0 *$ & $90,2 \pm 13,7$ & $108,3 \pm 14,4^{*}$ & $115,5 \pm 18,9^{*}$ & $110,9 \pm 13,0$ \\
\hline Вариант «А+Б» $(n=46)$ & $131,2 \pm 15,3$ & $128,7 \pm 16,6$ & $99,5 \pm 11,2^{*}$ & $95,1 \pm 12,2$ & $115,4 \pm 9,7^{*}$ & $128,4 \pm 16,9^{*}$ & $107,0 \pm 18,0$ \\
\hline $\begin{array}{l}\text { Вариант «A+B» } \\
(\mathrm{n}=143)\end{array}$ & $139,8 \pm 16,1$ & $132,2 \pm 14,8$ & $99,5 \pm 11,9^{*}$ & $95,1 \pm 11,8^{*}$ & $109,5 \pm 11,9^{*}$ & $127,2 \pm 16,0^{*}$ & $110,8 \pm 13.1$ \\
\hline $\begin{array}{l}\text { Вариант «A+Б+B» } \\
(n=56)\end{array}$ & $140,4 \pm 12,1$ & $131,3 \pm 15,9$ & $103,1 \pm 14,6^{*}$ & $96,1 \pm 9,2^{*}$ & $116,3 \pm 9,8^{*}$ & $131,5 \pm 18,6^{*}$ & $120,0 \pm 10,9$ \\
\hline Вариант «B» $(\mathrm{n}=70)$ & $133,8 \pm 11,8$ & $133,9 \pm 17,6$ & $98,7 \pm 10,5^{*}$ & $93,4 \pm 10,4^{*}$ & $110,4 \pm 8,1^{*}$ & $124,6 \pm 19,5^{*}$ & $109,1 \pm 11,1$ \\
\hline $\begin{array}{l}\text { Группа сравнения } \\
(\mathrm{n}=90)\end{array}$ & $136,0 \pm 15,7$ & $130,1 \pm 11,7$ & $90,1 \pm 12,5$ & $87,2 \pm 11,4$ & $102,9 \pm 12,0$ & $111,1 \pm 9,8$ & $111,8 \pm 14,7$ \\
\hline
\end{tabular}


к группе сравнения улучшили результаты операций хирургической коррекции митральных пороков.

Таким образом, была усовершенствована методика анестезиологического обеспечения операций по следующим направлениям:

а) проведение инфузионно-трансфузионной терапии (стимуляция диуреза, контроль водного баланса, сочетание ОНГ до ИК и снижение гемодилюции за счет ретроградного заполнения оксигенатора аутокровью);

б) использование методов эксфузии аутокрови и их комбинаций, изменение тактики инфузионной гемостатической терапии;

в) контроль ЦВД и поддержание АДср при различных методах эксфузии аутокрови.

Усовершенствованная методика позволила повысить качество хирургического лечения МП в условиях ИК.

\section{Литература}

1. Кровозберігаюча технологія при хірургічному лікуванні мітральних вад серця в умовах штучного кровообігу / Лазоришинець В. В., Попов В. В., Гуменюк Б. Н. та ін. // Журнал Національної академії медичних наук України. - 2016. - Том 22, № 1.- С. 80-86.

2. Кровосберегающая технология в хирургии митральных пороков сердца / Лазоришинец В. В., Попов В. В., Гуменюк Б. Н. и др. // Кардиология в Беларуси. - 2016. T. 8, № 3. - C. 21-25.
3. Intraoperative blood requirements and allogeneic blood transfusion in cardioanesthesia. Data analysis of 7729 patients in 12 cardiac surgical clinics / W. Dietrich, J. U. Luth, J. Kormann [et al.] // Anaesthesist. - 1999. - Vol. 48, № 12 . - P. $876-883$.

4. Handbook of Transfusion Medicine / Editor D B L McClelland. - London : TSO, 2007. - Vol. 31, № 15. - P. 26-27.

5. Autologous blood transfusion in elective cardiac valve operations // Lewis C. E. [et al.] // J. Card. Surg. - 2005. Vol. 20. - P. 513-518.

6. Nydegger U. Transfusion dependency in cardiac surgery update 2006 / U. Nydegger // Swiss Med. Wkly. - 2006. Vol. 136. - P. 781-788.

7. Perioperative blood transfusion and blood conservation in cardiac surgery / Spiess B. D. [et al.] // Annals of Thoracic Surgery. - 2007. - Vol. 83. - P. 27-86.

8. Transfusion triggers for guiding rbc transfusion for cardiovascular surgery: a systematic review and meta-analysis / Curley G. F., Shehata N., Mazer C. D. [et al.] // Crit care Med. - 2014. - Vol. 42. - P. 2611-24.

9. Variation in transfusion rates within a single institution: exploring of blood product transfusion in patients undergoing cardiac surgery / Cote C., Macleod J. B., Yip A. M. et al. // J Thorac Cardiovasc Surg. - 2015. Vol. 149. - P. 297-302.

10. Effect of hospital culture on blood transfusion in cardiac procedures / Jin R., Zelinka E. S., McDonald J. et al. // Ann Thorac Surg. - 2013. - Vol. 95. - P. 1269-74.

\title{
Bloodreserved technology during surgical treatment of mitral valve dedeases
}

\author{
Gumenyuk B. N., Popov V. V., Gumenyuk O. B., Spisarenko S.P., Lazorishinetz V. V.
}

National M. M. Amosov Institute of Cardiovascular Surgery National Academy of Medical Sciences of Ukraine (Kyiv)

Usage of donor blood during operations of mitral valve replacement with usage of donor blood components is associated with different possible complications, which stimulates to search measures for not using шe. In department of acquired heart diseases of NICVS AMS Ukraine from 01.01.2000. till 01.01.2017 were performed 717 isolated mitral valve replacements, in treatment of whom during hospital period components of donor blood were not used. Methodics of anesteological and perfusiological treatment in mitral valve replacemnt with cardiopulmonary bypass was described, and alsopeculiarities in intensive care unit. Hospital mortality was $1,4 \%$, duration of stay in intensive care unit 54,2 $\pm 4,7$ hours, duration of stay in surgical department - 7,9 $\pm 0,7$ days. At discharge this group of patients had moderate anemia. Usage of developed methodics in clinical practice allowed to get good clinical effect, avoiding posttransfusion complications on hospital stage.

Key words: cardiopulmonary bypass, method without using donor blood, correction of mitral valve.

\section{Кровосберігаюча технологія при хірургічному лікуванні мітральних вад в умовах штучного кровообігу}

\author{
Гуменюк Б. М., Попов В. В., Гуменюк О. Б., Списаренко С. П., Лазоришинець В. В. \\ ДУ «Національний інститут серцево-судинної хірургії імені М. М. Амосова НАМН» (Київ)
}

Застосовування під час операцій протезування мітрального клапана з ШК компонентів донорської крові пов’язано з різноманітними можливими ускладненнями, що потребує пошуку альтернативних заходів для уникнення їх використання. У відділенні хірургії набутих вад серця НІССХ НАМН з 01.01.2000 до 01.01.2017 виконано ізольоване протезування мітрального клапана у 717 пацієнтів, при лікуванні яких на госпітальному етапі не використовувалися компоненти донорської крові. Описано методику проведення анестезіологічних і перфузіологічних заходів при протезуванні мітрального клапана з ШК, а також особливості ведення у відділенні інтенсивної терапії. Госпітальна летальність склала $1,4 \%$, час перебування у відділенні інтенсивної терапії - 54,2 4,7 години, час перебування в хірургічному стаціонарі $-7,9 \pm 0,7$ доби. При виписці у цієї групи хворих спостерігалася помірна анемія. Впровадження описаної методики дозволило отримати добрий клінічний ефект, без трансфузійних ускладнень на госпітальному етапі.

Ключові слова: штучний кровообіг, методика без використання донорської крові, корекція мітральної вади. 